Research letter

\title{
Investigation of emotional burnout in bank employees working in «person-to-person» system
}

\author{
Marina V. Kiseleva
}

Saratov Socio-Economic Institute, Plekhanov Russian University of Economics, Saratov, Russia

Received 12 March 2018, Revised 15 May 2018, Accepted 26 June 2018

(C) 2018, Kiseleva M.V

(C) 2018, Russian Open Medical Journal

Abstract: This study was designed to evaluate the intensity of emotional burnout (EB) in bank employees who directly interact with clients. One hundred and seventeen bank employees (90 women and 27 men; 21-54 years old), whose job directly involves client service, had their level of EB measured using a psychodiagnostic test proposed by Boyko (1996). This tool allows identifying three phases of EB: tension, resistance, and exhaustion. It was shown that a greater proportion of respondents (69.3\%) have prevalent features of resistance phase in EB. Exhaustion phase is also notable, with its symptoms present in $53.9 \%$ respondents. Tension phase was the least prevalent in the evaluated group of bank employees (only present in $23.1 \%$ cases). Analysis of EB in bank employees engaged in direct interaction with clients has shown that this group of individuals is characterized primarily by symptoms of resistance phase, triggered by the excessive emotional burden and constant stress.

Keywords: emotional burnout, bank workers.

Cite as Kiseleva MV. Investigation of emotional burnout in bank employees working in «person-to-person» system. Russian Open Medical Journal 2018; 7 : e0307.

Correspondence to Marina V. Kiseleva. E-mail: marina.balashova@list.ru.

\section{Introduction}

Professional activity takes a great deal of time in individual's life, making a direct impact on his or her behavior, interests and personal qualities. Psychological overload and emotional stress related to the execution of official responsibilities may lead to distortion of individual's personality, which will particularly manifest itself as an emotional burnout (EB) [1].

BS is developed by personality as a psychological defense mechanism consisting of total or partial emotional shutdown in response to certain traumatizing influences. The existence of such phenomenon was first mentioned by Freudenberger [2]. However, EB-related research begun only when a study by Maslach [3]. About one-third of people in general population may suffer from features of EB [4].

People working in "person-to-person» system are the most predisposed to the development of this syndrome $[5,6]$; an example of vulnerable populations are doctors, teachers, and psychologists, though EB may be present in other professions too [4, 7-10]. Russian studies which dealt with this phenomenon primarily evaluated people of these occupations [11-17], while prevalence and specifics of EB in banking personnel remain poorly studied.

This study was aimed at evaluation of EB intensity in bank workers directly interacting with clients.

\section{Material and Methods}

One hundred and seventeen specialists (90 women and 27 men) working in a bank, aged between 21 and 54 years, whose job is directly related to client service with a record of 6 months to 15 years were enrolled in this study.

The study involved psychodiagnostic testing of EB level using the method proposed by Boyko [18], which allows detection of emotional disturbances and their dysfunctional consequences in terms of professional activity and coworker interaction. Burnout represents acquired stereotype of emotional or more often professional behavior. Professional burnout is a kind of person's professional deformation. Phases of the development of the EB in the concept of Boyko are similar to the phases of development of the general adaptive syndrome $[18,19]$. Tension serves as a starting mechanism that triggers the formation of the EB. This stage is determined by the stable intensity of the stress factors. The next phase is the phase of resistance. However, in fact, the resistibility to increasing stress and burnout begins from the moment of jitteriness. This is natural, as a person deliberately or unknowingly strives for psychological comfort and for reducing the pressure of the surrounding circumstances. The phase of exhaustion is characterized by more or less pronounced decrease in the total energy tone and weakening of the nervous system. Emotional protection in the form of EB becomes an integral attribute of the individual.

The method consists of filling the 84-item questionnaire by participants, with each question unambiguously answered as "yes» or "no" (Appendix A). During the creation of this questionnaire, every possible answer was rated by experts with a certain amount of points (Appendix B). Method and interpretation of test results are described in detail in Appendix $\mathrm{B}$. The tool allows distinguishing three phases of EB («tension», «resistance», «exhaustion») with each one having four corresponding symptoms 
(Table 1). Questions are grouped into three scales, making it possible to diagnose the formation of each of the phases. Each scale is divided into four subscales. The total score obtained for each of these subscales allows us judging about the level and degree of each phase formation. According to the results of stress development stages, we can estimate their relative role or influence on the EB development.

\section{Results}

Results of processing the questionnaires filled by respondents are shown in Tables 2 and 3.

It is shown that the highest number of respondents with $E B$ present with dominating features of resistance phase (fully developed or developing in $69.3 \%$ of respondents; Table 3), particularly «inadequate emotional specific reaction» and "professional duties reduction» symptoms are present in $69.2 \%$ and $61.6 \%$, respectively (Table 2). «Emotional and moral disorientation» and "widening of emotional thriftiness area» were significantly less prevalent (Table 2).

Exhaustion phase is also rather common: it is fully developed or is developing in $53.9 \%$ of respondents (Table 3). This phase most commonly includes symptoms of the emotional deficiency, emotional isolation, and personal detachment.

Tension phase is the least prevalent in the studied group of banking professionals. It is developed or developing only in $23.1 \%$ of respondents (Table 3).

It is worth to note that two persons ( 22 and 54 years old, 0.5 and 15.0 years of job experience respectively) had features of all three EB phases, which may be explained by difficult adaptation period in the first case and by a prolonged influence of psychological stress in absence of measures required to restore psychological balance.

\section{Discussion}

Factors influencing the development of EB in bank workers directly involved in client service include the following: adaptation to changing the workplace, constant psycho-emotional overload related to interaction with people, high responsibility, psychologically difficult interaction with clients burdened with negative emotions and the negative impact of conflicts with other staff members. Internal factors include interaction intensity and personality type (extrovert or introvert). High prevalence of EB symptoms in bank workers was already reported by foreign researchers [20].

Age and work record are also important factors for the development of EB $[9,21]$. However, our study didn't show any association between $\mathrm{EB}$ and age of respondents or their work record.

Psychological intervention with the employee, which should include assistance in realization of his problems and identification of possible solutions, among other things, is one of the ways to combat EB [22, 23]. The direct supervising manager should have an important role in this by providing constant psychological support to personnel, dynamically overseeing work performance and interaction with colleagues for every worker, and promptly take measures necessary to prevent EB in them. As a rule, prevention and rehabilitation measures aimed at relieving tension, enhancing professional motivation in workers and improving the balance between efforts and rewards. It should be noted that payment is only insignificantly associated with job satisfaction [24].
Table 1. Symptoms of EB development stages (according to Boyko [18])

\begin{tabular}{|c|c|}
\hline Phase & Symptoms \\
\hline \multirow[t]{4}{*}{ Tension } & Stressful experience \\
\hline & Dissatisfaction with oneself \\
\hline & Feeling of "being trapped in a cage" \\
\hline & Anxiety and depression \\
\hline \multirow[t]{4}{*}{ Resistance } & Inadequate emotional specific reaction \\
\hline & Emotional and moral disorientation \\
\hline & Widening of emotional thriftiness area \\
\hline & Professional duties reduction \\
\hline \multirow[t]{4}{*}{ Exhaustion } & Emotional deficiency \\
\hline & Emotional isolation \\
\hline & Personal detachment (depersonalization) \\
\hline & Psychosomatic and psycho-vegetative disorders \\
\hline
\end{tabular}

There is a consolidated opinion that psycho-emotional exhaustion is the most important aspect of EB [25-27]. Women are more prone to development of this condition when compared to men $[4,28]$. Prevalence of women in our study hasn't allowed us to study gender-related aspects of EB in our cohort of bank service workers.

An important role in counteracting EB belongs to the person himself $[29,30]$. A person should realize the necessity of regular rest periods to restore physical and spiritual energy, learn how to relax, learn to set achievable goals for himself, search for ways towards self-development and self-improvement, while widening the area of interests, thereby creating a distraction from existing problems.

It is worth to note that respondents aged primarily 21-29 years old participated in this study. Our data, which shows a high prevalence of resistance phase, makes evident that further development of EB will continue under influence of such stress factors unless preventive measures are taken. Psychological disturbance may lead to serious nervous system disorders, which makes timely control of stress factors necessary.

\section{Conclusion}

Analysis of EB in bank workers directly involved in client service has shown that this group of people is characterized by the development of resistance phase symptoms, caused by excessive emotional overload and regular stress. Development of this syndrome is also influenced by the personal perception of the environment; for example, excessive sensitivity and «closed» personality accelerates burnout development.

\section{Limitations}

In the sample, there were more women than men. We did not analyze gender differences.

\section{Ethical approval}

All procedures performed in studies involving human participants were in accordance with the ethical standards of the institutional research committee and with the 1964 Helsinki declaration and its later amendments or comparable ethical standards.

\section{Conflict of interest}

The author declares that she has no conflict of interest. 
Table 2. Prevalence of EB symptoms with varying degrees of severity (with point values) in respondents

\begin{tabular}{|c|c|c|c|c|}
\hline \multirow[t]{2}{*}{ Symptoms } & \multicolumn{4}{|c|}{ Symptom severity, points } \\
\hline & $\leq 9$ & $10-15$ & $16-20$ & $>20$ \\
\hline Stressful experience & $63(53.8)$ & $18(15.4)$ & $18(15.4)$ & $18(15.4)$ \\
\hline Dissatisfaction with oneself & $81(69.2)$ & $18(15.4)$ & $18(15.4)$ & 0 \\
\hline Feeling of "being trapped in a cage" & $72(61.5)$ & $45(38.5)$ & 0 & 0 \\
\hline Anxiety and depression & $99(84.6)$ & $9(7.7)$ & 0 & $9(7.7)$ \\
\hline Inadequate emotional specific reaction & $9(7.7)$ & $27(23.1)$ & $63(53.8)$ & $18(15.4)$ \\
\hline Emotional and moral disorientation & $54(46.2)$ & $54(46.2)$ & 0 & $9(7.7)$ \\
\hline Widening of emotional thriftiness area & $81(69.2)$ & 0 & $9(7.7)$ & $27(23.1)$ \\
\hline Professional duties reduction & $18(15.4)$ & $27(23.1)$ & $27(23.1)$ & $45(38.5)$ \\
\hline Emotional deficiency & $54(46.2)$ & $27(23.1)$ & $27(23.1)$ & $9(7.7)$ \\
\hline Emotional isolation & $9(7.7)$ & $63(53.8)$ & $36(30.8)$ & $9(7.7)$ \\
\hline Personal detachment (depersonalization) & $72(61.5)$ & $9(7.7)$ & $18(15.4)$ & $18(15.4)$ \\
\hline Psychosomatic and psycho-vegetative disorders & $90(76.9)$ & $18(15.4)$ & 0 & $9(7.7)$ \\
\hline
\end{tabular}

Data are presented as an absolute number of respondents and their percentage of total study subjects - no. (\%).

Table 3. Levels of development of emotional burnout phases in respondents

\begin{tabular}{|c|c|c|c|}
\hline \multirow[t]{2}{*}{ Phase name } & \multicolumn{3}{|c|}{ Phase status } \\
\hline & Not developed & Developing & Developed \\
\hline Tension & $90(76.9)$ & $18(15.4)$ & $9(7.7)$ \\
\hline Resistance & $36(30.8)$ & $36(30.8)$ & $45(38.5)$ \\
\hline Exhaustion & $54(46.2)$ & $36(30.8)$ & $27(23.1)$ \\
\hline
\end{tabular}

Data are presented as an absolute number of respondents and their percentage of total study subjects - no. (\%).

\section{References}

1. Dalakova AS, Dubovy LM. The mechanism of formation of prerequisites of emotional burnout syndrome and factors affecting this syndrome. Vestnik Kostromskogo Gosudarstvennogo Universiteta 2009; 15: 336-343. Russian. https://elibrary.ru/item.asp?id=15141515.

2. Freudenberger M. Staff Burn-out. Journal of Social Issues 1974; 30: 159-166. https://dx.doi.org/10.1111/j.1540-4560.1974.tb00706.x.

3. Maslach C. Burnout: A social psychological analysis. In: The burnout syndrome. J.W. Jones eds. London, UK: London House, 1981: 30-53.

4. Heinke W, Dunkel $P$, Brähler E, Nübling $M$, Riedel-Heller S, Kaisers UX. Burnout in anesthesiology and intensive care: Is there a problem in Germany? Der Anaesthesist 2011; 60: 1109-1118. https://dx.doi.org/10.1007/s00101-011-1947-3.

5. Maslach C, Schaufeli WB, Leiter MO. Job burnout. Annual Review of Psychology 2001; 52: 397-422. https://dx.doi.org/10.1146/annurev.psych.52.1.397.

6. Tereshechkina EA. Emotional burnout syndrome and satisfaction of labor specialists in occupations "man-man" and "man-technician". Mezhdunarodnyy Studencheskiy Nauchnyy Vestnik 2016; (5-1): 129129a. https://elibrary.ru/item.asp?id=26142920.

7. De la Fuente Solana El, Aguayo Extremera R, Vargas Pecino C, Cañadas de la Fuente GR. Prevalence and risk factors of burnout syndrome among Spanish police officers. Psicothema 2013; 25: 488-493. https://dx.doi.org/10.7334/psicothema2013.81.

8. Hernández L, Fernández B, Ramos F, Contador I. El síndrome de burnout en funcionarios de vigilancia de un centro penitenciario [The burnout syndrome in prison officers]. Interntional Journal of Clinical and Health Psychology 2006; 6: 599-611. http://www.redalyc.org/html/337/33760306.

9. Longas J, Chamarro A, Riera J, Cladellas R. La incidencia del contexto interno docente en la aparición del Síndrome del Quemado por el Trabajo en profesionales de la enseñanza [The impact of the internal teaching context on the development of burnout syndrome in teaching professionals]. Revista de Psicología del Trabajo y de las Organizaciones 2012; 28: 107-118. https://dx.doi.org/10.5093/tr2012a9.

10. Vuorensyrjä M, Mälkiä M. Nonlinearity of the effects of police stressors on police officer burnout. Policing: a International Journal of Police Strategies and Management 2011; 34: 382-402. https://dx.doi.org/10.1108/13639511111157474
11. Chovdyrova GS, Osipova MI, Klimenko TS. Psychological attributes hindering the person's emotional burnout as a syndrome of chronical stress development. Psycho-Pedagogics in Law Enforcement Agencies 2014; (3): 88-90. Russian. https://elibrary.ru/item.asp?id=22529115.

12. Dorofeeva SG, Shelukhina AN, Petrova LI, Konoplya EN, Mansimova OV. Syndrome of emotional burnout among social workers. Aktualnye Nauchnye Issledovaniya v Sovremennom Mire 2017; (3-7): 95-97. Russian. https://elibrary.ru/item.asp?id=28982965.

13. Igovskaya A, Buslavskaya I. Psychotherapeutic help and prevention of medical workers in the emotional burnout syndrome. Sovremennyy Nauchnyy Vestnik 2014; 2: 106-111. Russian. https://elibrary.ru/item.asp?id=25636348.

14. Jefferson MD. Looking at teacher burnout. Psychology in Economics and Management 2014; 1 : 86-88.

15. Komarevtseva IV. The dynamics of tolerance to the emotional burnout syndrome among teachers of the system of special education in the process of preventive work. Russian Psychological Journal 2014; 11(2): 51-60. Russian. https://elibrary.ru/item.asp?id=21946703.

16. Mikolaevsky DV. Burnout syndrome among physicians. Razvitie Professionalizma 2016; (1): 200-201. Russian https://elibrary.ru/item.asp?id=28886887.

17. Visotskaya N, Cherkashina E, Katcin O, Lisina L. Studies on university professors' emotional burnout. Procedia - Social and Behavioral Sciences 2015; 214: 769-778. https://doi.org/10.1016/j.sbspro.2015.11.716.

18. Boyko VV. Energy of emotions in communication: a view of oneself and others. Moscow, Russia: Filin, 1996. Russian.

19. Bulatevych N. Teacher's burnout syndrome: the phenomenology of the process. Pol J Public Health 2017; 127(2): 62-66. https://doi.org/10.1515/pjph-2017-0014.

20. Amigo I, Asensio E, Menéndez I, Redondo S, Ledesma JA. Working in direct contact with the public as a predictor of burnout in the banking sector. Psicothema 2014; 26: 222-226. https://dx.doi.org/10.7334/psicothema2013.282.

21. Gil-Monte P. El síndrome de quemarse por el trabajo [The burnout syndrome]. Madrid: Pirámide, 2005.

22. Boyd CM, Tuckey MR, Winefield AH. Perceived effects of organizational downsizing and staff cuts on the stress experience: the 
role of resources. Stress Health 2014; 30: 53-64. https://dx.doi.org/10.1002/smi.2495.

23. Frost $P$, Robinson $S$. The toxic handler: Organizational hero and casualty. Harv Bus Rev 1999; 77: 96-106. https://www.ncbi.nlm.nih.gov/pubmed/10539211.

24. Judge TA, Piccolo RF, Podsakoff NP, Shaw JC, Rich BL. The relationship between pay and job satisfaction: a meta-analysis of the literature. Journal of Vocational Behavior 2010; 77: 157-167. https://dx.doi.org/10.1016/i.jvb.2010.04.002.

25. González-Romá V, Schaufeli WB, Bakker AB, Lloret S. Burnout and work engagement: Independent factors or opposite poles? Journal of Vocational Behavior 2006; 68: 165-174. https://dx.doi.org/10.1016/i.jvb.2005.01.003.

26. Halbesleben JR, Demerouti E. The construct validity of an alternative measure of burnout: Investigating the English translation of the Oldenburg Burnout Inventory. Work and Stress 2005; 19: 208-220. https://dx.doi.org/10.1080/02678370500340728.

27. Lee RT, Seo S, Hladkyj S, Lovell BL, Schwartzmann L. Correlates of physician burnout across regions and specialties: A meta-analysis. Human Resources for Health 2013; 11: 48-90. https://dx.doi.org/10.1186/1478-4491-11-48.

28. Ayuso JA, Guillén CL. Burnout y mobbing en Enseñanza Secundaria [Burnout and mobbing in high school]. Revista Complutense de Educación 2008; 19 197-173. http://revistas.ucm.es/index.php/RCED/article/view/RCED0808120157 A.

29. Erdogan B, Bauer TN, Truxillo DM, Mansfield L. Whistle while you work: a review of the life satisfaction literature. Journal of Management 2012; 38: 1038-1083. https://dx.doi.org/10.1177/0149206311429379.

30. Pillay HK, Goddard R, Wilss LA. Well-being, burnout and competence: Implications for teachers. Australian Journal of Teacher Education 2005; 30: 22-33. https://dx.doi.org/10.14221/ajte.2005v30n2.3.

Author:

Marina V. Kiseleva - PhD student, Department of Personnel Management and Psychology, Saratov Socio-Economic Institute, Plekhanov Russian University of Economics, Saratov, Russia. https://orcid.org/0000-00016838-2357. 
Appendix A. Questionnaire for determining a degree of emotional burnout by Boyko (1996) [18]

1. Organizational limitations at work constantly make me nervous, worried or stressed out.

2. Today I am no less satisfied by my profession than in beginning of my career.

3. I was wrong in my choice of profession or job area (I'm in the wrong place).

4. I am concerned that I work worse than before (less productive, less efficiently, slower).

5. Interaction with partners depends on whether my mood is good or bad.

6. The well-being of my partners doesn't really depend on my professional competence.

7. When I come home from work, I want to be alone for some time (about 2-3 hours) not to speak with anyone.

8. When I feel tired or tense, I want to solve my partner's problems as soon as possible (to finish our interaction).

9. I think that emotionally I am unable to fulfill my professional duty to partners.

10. My job dulls my emotions.

11. I am sincerely tired of people's problems which I encounter at work.

12. Sometimes I do not sleep well because of job-related experiences.

13. Interaction with partners makes me very tense.

14. Interaction with people brings me less and less satisfaction.

15. I would change my place of work if I had an opportunity.

16. I am frequently distressed that I am unable to properly provide professional support, service or help to partners.

17. I am always able to avoid bad mood to influence my professional contacts.

18. I am very sad if something is not right in my interactions with a business partner.

19. I am so tired at work that at home I try to communicate as little as possible.

20. Because of lack of time, tiredness or tension I frequently give less attention to partner than it is required.

21. Sometimes even the trivial conversations at work irritate me.

22. I calmly respond to reasonable pretensions of partners.

23. Interaction with partners makes me avoid people.

24. My mood is ruined when I remember about certain co-workers and partners.

25. Conflicts and differences with co-workers require much effort and emotion.

26. It is getting harder and harder to establish and maintain business contacts.

27. Work environment seems very difficult and complex to me.

28. I frequently experience work-related anxiety: something must happen, how to avoid mistakes, will I be able to do everything right, am I going to be fired etc

29. If partner is unpleasant to me, I try to limit my interactions with him or limit a degree of attention which I give to him.

30. At work I adhere to the following principle: «No good deed goes unpunished».

31. At home I willingly talk about my job.

32. There are days when my emotional status has negative impact on my productivity (my performance decreases, quality of my work decreases, conflicts happen).

33. Sometimes I feel that I need to react emotionally to my partner, but I can't.

34. I worry about my job.

35. Work partners receive attention and care which outweighs the gratitude they give in return.

36. I feel uneasy when I think about my work: I experience heartache, headache, hypertension.

37. I have good (adequate) relationship with my direct superior

38. I often feel glad when I see how my job benefits people.

39. Recently (or always) I fail at work.
40. Some aspects of my job bring me deep disappointment and depression.

41. There are days when interaction with partners is less successful than usual.

42. I divide business partners into "good ones" and "bad ones"

43. I'm so tired of work that I try to limit my interactions with friends and associates.

44. I am usually interested in my partner's personality beyond businessrelated issues.

45. Usually I come to work refreshed, well-rested and in good mood.

46. Sometimes I understand that I work with partners without emotional involvement.

47. Sometimes I work with such unpleasant people that I unwillingly wish bad things happen to them.

48. Sometimes after interaction with unpleasant partners I experience worsening of my physical and emotional well-being.

49. I experience constant physical and psychological overload at work.

50. Success at work inspires me.

51. Situation at work seems hopeless (almost hopeless) for me.

52. I am restless because of my job,

53. During last year partners complained about me at least once.

54. I spare my nerve by not taking many of the things which happen to partners close to my heart.

55. I often bring home negative emotions from work.

56. I often have to force myself to work.

57. Formerly I was more responsive and attentive to partners than now.

58. When I work with people, I adhere to the following rule: don't waste your nervous system, spare your health.

59. Sometimes I go to work with a heavy feeling of being bored with everything and wishing not to see and hear from anyone.

60. After a busy day at work I feel ill.

61. The group of people that I work with is very difficult.

62. Sometimes I feel that the yield of my work is insignificant compared against my efforts.

63. I would be happier if I was lucky with my job.

64. I'm desperate about serious problems at work.

65. Sometimes I treat my partners unlike I would want to be treated myself.

66. I condemn partners who suppose they should receive special treatment and leniency.

67. After work I often have no energy for household affairs.

68. Usually I wish the time would run quicker and the work day would be over.

69. Usually I sincerely care about condition, requests and needs of my partners.

70. When I work with people I usually create a mental barrier which shields me from their suffering and negative emotions.

71. Work with people (partners) disappointed by deeply.

72. I often take medications to restore my energy.

73. Usually my working day is calm and easy.

74. At work I demand more of myself than I am able to achieve due to certain circumstances.

75. My career is successful.

76. I am very nervous about everything related to my job.

77. I don't want to see or hear anything about some of my constant partners.

78. I admire my colleagues who totally devote themselves to people (partners), while forgetting about their own interests.

79. My work-related fatigue usually has little impact (or no impact at all) on my interactions with friends and relatives.

80. If it is possible, I pay less attention to partners, but in such way that they won't notice it.

81. My nerve often fails me when I talk to people at work.

82. I lost interest to everything (almost everything) which happens at work.

83. Professionally, working with people negatively affected me - it made me bitter, nervous and dulled my emotions.

84. Working with people disrupts my health. 
Appendix B. Processing and interpretation of results for Boyko emotional burnout evaluation system [18]

Processing of completed questionnaires:

i) Points value for each of 12 emotional burnout (EB) symptoms is calculated using coefficients from lookup table (Appendix C). For example, positive answer to question №13 has value of 3 points regarding the first symptom, and negative answer to question №73 has value of 5 points; sum total is calculated and quantitative measure of symptom intensity is determined.

ii) Sum total for symptoms of every three phases of $E B$ is calculated. Phases and their corresponding symptoms are shown in Table 1.

iii) Final determinant of EB is calculated - sum of point values of all 12 symptoms.

This method provides a complete picture of EB. Intensity of every symptom is measured within range of 0-30 points:

- 9 points or less - absent symptom,

- 10-15 points - developing symptom,

- $16-20$ points - developed symptom.

- 20 points or more - such symptoms are considered to be dominating in a current phase or in entire EB.

The next step in interpretation of questionnaire results is the evaluation of phases of $E B$ with their values measured within range of 0 to 120 points. Comparison of point values calculated for every phase is unjustified, because it doesn't allow judging their contribution to development of EB as a whole. The phenomena which constitute those phases are essentially different: reaction towards internal and external factors, psychological defense mechanisms, status of nervous system. Quantitative parameters only allow us to judge a degree of development for every phase, and which phase is more or less developed:

- 36 points or less - phase has not developed;

- 37-60 points - phase is developing;

- 61 points or more - phase had developed.

Psychodiagnostic conclusion includes the answers to following questions:

- which symptoms dominate;

- which developed and dominating symptoms accompany «exhaustion»;

- can the «exhaustion» (if it is found) be explained by professional factors invloved in "burnout» symptoms or personal factors;

- which symptom (or symptoms) most negatively affect emotional condition of a person;

- in which direction workplace environment should be managed to decrease nervous tension;

- which signs and aspects of person's behavior require correction to avoid emotional «burnout» damage to person himself, professional activity and partners. 
Appendix C. Lookup table for every positive answer in questionnaire and corresponding coefficients for calculation of point's value for each of 12 emotional burnout symptoms (Boyko, 1996 [18])

\begin{tabular}{|c|c|c|c|c|c|c|c|c|c|c|c|c|}
\hline Questions & 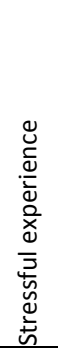 & 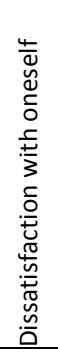 & 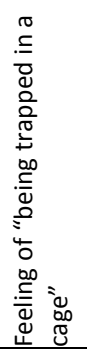 & 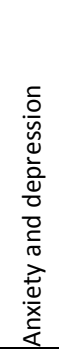 & 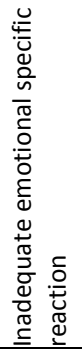 & 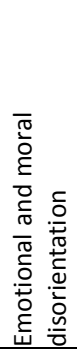 & 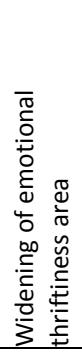 & 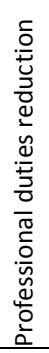 & $\begin{array}{l}\text { ป̀ } \\
\frac{0}{0} \\
\frac{0}{0} \\
\frac{0}{4} \\
\frac{0}{0} \\
\frac{\pi}{0} \\
\frac{0}{0} \\
\frac{1}{0} \\
\frac{E}{4} \\
\end{array}$ & 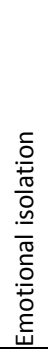 & 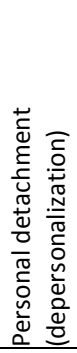 & 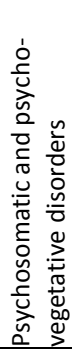 \\
\hline 1 & +2 & & & & & & & & & & & \\
\hline 2 & & -3 & & & & & & & & & & \\
\hline 3 & & & +10 & & & & & & & & & \\
\hline 4 & & & & +2 & & & & & & & & \\
\hline 5 & & & & & +5 & & & & & & & \\
\hline 6 & & & & & & +10 & & & & & & \\
\hline 7 & & & & & & & +2 & & & & & \\
\hline 8 & & & & & & & & +5 & & & & \\
\hline 9 & & & & & & & & & +3 & & & \\
\hline 10 & & & & & & & & & & +2 & & \\
\hline 11 & & & & & & & & & & & +5 & \\
\hline 12 & & & & & & & & & & & & +3 \\
\hline 13 & +3 & & & & & & & & & & & \\
\hline 14 & & +2 & & & & & & & & & & \\
\hline 15 & & & +5 & & & & & & & & & \\
\hline 16 & & & & +3 & & & & & & & & \\
\hline 17 & & & & & -3 & & & & & & & \\
\hline 18 & & & & & & -3 & & & & & & \\
\hline 19 & & & & & & & +10 & & & & & \\
\hline 20 & & & & & & & & +5 & & & & \\
\hline 21 & & & & & & & & & +2 & & & \\
\hline 22 & & & & & & & & & & +3 & & \\
\hline 23 & & & & & & & & & & & +3 & \\
\hline 24 & & & & & & & & & & & & +2 \\
\hline 25 & +2 & & & & & & & & & & & \\
\hline 26 & & +2 & & & & & & & & & & \\
\hline 27 & & & +2 & & & & & & & & & \\
\hline 28 & & & & +5 & & & & & & & & \\
\hline 29 & & & & & +10 & & & & & & & \\
\hline 30 & & & & & & +3 & & & & & & \\
\hline 31 & & & & & & & -20 & & & & & \\
\hline 32 & & & & & & & & +2 & & & & \\
\hline 33 & & & & & & & & & +5 & & & \\
\hline 34 & & & & & & & & & & -2 & & \\
\hline 35 & & & & & & & & & & & +3 & \\
\hline 36 & & & & & & & & & & & & +5 \\
\hline 37 & -3 & & & & & & & & & & & \\
\hline 38 & & -10 & & & & & & & & & & \\
\hline 39 & & & +2 & & & & & & & & & \\
\hline 40 & & & & +5 & & & & & & & & \\
\hline 41 & & & & & +2 & & & & & & & \\
\hline 42 & & & & & & +5 & & & & & & \\
\hline 43 & & & & & & & +5 & & & & & \\
\hline 44 & & & & & & & & -2 & & & & \\
\hline 45 & & & & & & & & & -5 & & & \\
\hline 46 & & & & & & & & & & +3 & & \\
\hline 47 & & & & & & & & & & & +5 & \\
\hline 48 & & & & & & & & & & & & +3 \\
\hline 49 & +10 & & & & & & & & & & & \\
\hline 50 & & -5 & & & & & & & & & & \\
\hline 51 & & & +5 & & & & & & & & & \\
\hline 52 & & & & +10 & & & & & & & & \\
\hline 53 & & & & & +2 & & & & & & & \\
\hline 54 & & & & & & +2 & & & & & & \\
\hline
\end{tabular}




\begin{tabular}{|c|c|c|c|c|c|c|c|c|c|c|c|c|}
\hline Questions & 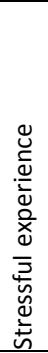 & 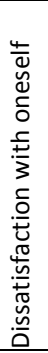 & 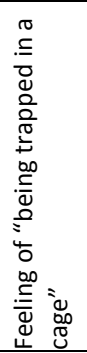 & 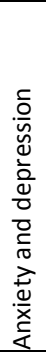 & 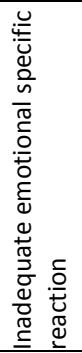 & 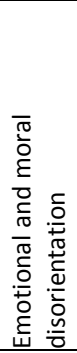 & 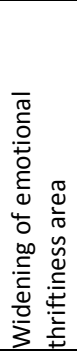 & 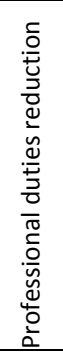 & 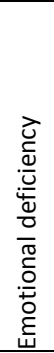 & 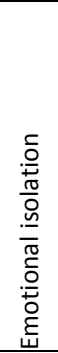 & 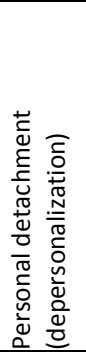 & 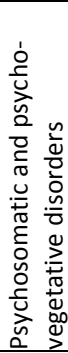 \\
\hline 55 & & & & & & & +3 & & & & & \\
\hline 56 & & & & & & & & +3 & & & & \\
\hline 57 & & & & & & & & & +3 & & & \\
\hline 58 & & & & & & & & & & +5 & & \\
\hline 59 & & & & & & & & & & & +5 & \\
\hline 60 & & & & & & & & & & & & +2 \\
\hline 61 & +5 & & & & & & & & & & & \\
\hline 62 & & +5 & & & & & & & & & & \\
\hline 63 & & & +1 & & & & & & & & & \\
\hline 64 & & & & +2 & & & & & & & & \\
\hline 65 & & & & & +3 & & & & & & & \\
\hline 66 & & & & & & +2 & & & & & & \\
\hline 67 & & & & & & & +3 & & & & & \\
\hline 68 & & & & & & & & +3 & & & & \\
\hline 69 & & & & & & & & & -10 & & & \\
\hline 70 & & & & & & & & & & +5 & & \\
\hline 71 & & & & & & & & & & & +2 & \\
\hline 72 & & & & & & & & & & & & +10 \\
\hline 73 & -5 & & & & & & & & & & & \\
\hline 74 & & +3 & & & & & & & & & & \\
\hline 75 & & & -5 & & & & & & & & & \\
\hline 76 & & & & +3 & & & & & & & & \\
\hline 77 & & & & & +5 & & & & & & & \\
\hline 78 & & & & & & -5 & & & & & & \\
\hline 79 & & & & & & & -5 & & & & & \\
\hline 80 & & & & & & & & +10 & & & & \\
\hline 81 & & & & & & & & & +2 & & & \\
\hline 82 & & & & & & & & & & +10 & & \\
\hline 83 & & & & & & & & & & & +10 & \\
\hline 84 & & & & & & & & & & & & +5 \\
\hline
\end{tabular}

